\title{
A participação econômica das mulheres no mercado de trabalho
}

\author{
La participación económica de las mujeres en el mercado de trabajo \\ The economic participation of women in the labor market
}

\author{
Agnes Martha da Silva ${ }^{1}$ \\ Patrícia Rodrigues Chaves da Cunha ${ }^{2}$
}

\begin{abstract}
Resumo
O mercado de trabalho pode ser entendido como uma relação de compra e venda da força de trabalho, sendo também um espaço econômico e social. Através deste contexto o presente trabalho tem como objetivo analisar a participação econômica da mulher no município de Pelotas. Por meio de uma investigação de caráter quantitativo, foram levantados dados e calculadas as categorias estatísticas como população economicamente ativa, população ocupada, taxas de atividade e desemprego, entre outros, utilizando-se, dentro disso a variável sexo. Desta forma, pretende-se compreender as transformações ocorridas nesta cidade, de 2000, 2010 e 2015 mensurando-se os níveis de absorção da força de trabalho feminina, neste período de tempo. Com base neste conjunto de fatores preocupa-se perceber a condição de ação da mulher dentro da esfera econômica do município. Assim, constatando a representatividade feminina no mercado de trabalho.
\end{abstract}

Palavras chaves: Desigualdades, Mercado de Trabalho, Mulheres, Pelotas/RS.

\section{Resumen}

El mercado de trabajo puede ser entendido como relación de compra y venta de fuerza de trabajo, siendo también un espacio económico y social. A partir de este contexto, el presente trabajo tiene como objetivo analizar la participación económica de la mujer en el municipio de Pelotas. Por medio de una investigación de tipo cuantitativo, fueron levantados datos y hechos los cálculos estadísticos para: población económicamente activa, población ocupada, tasas de actividad y desempleo, entre otros, utilizándose la variable sexo en dichas operaciones. De esta manera, se pretenden comprender las transformaciones ocurridas en esta ciudad en el periodo 2000, 2010 y 2015, midiéndose los niveles de absorción de fuerza de trabajo femenina durante ese tiempo. Sobre la base de ese conjunto de factores, la intención es analizar las condiciones de la acción de la mujer en la esfera económica del municipio; y la representatividad femenina en el mercado de trabajo.

Palabras clave: Desigualdades, Mercado de Trabajo, Mujeres, Pelotas/RS.

\begin{abstract}
The labor market can be understood as a relationship of buying and selling labor power, and as a economic and social space also. In this context, this article has as an objective analyzing the economic participation of women in the city of Pelotas. Through quantitative investigation methods, data has been collected and calculated on statistic categories such as economically active population, occupied population, activity and unemployment

\footnotetext{
${ }^{1}$ Graduanda de ciências sociais; Universidade Federal de Pelotas; Pelotas, Rio Grande do Sul; Brasil; agnes_marthas@hotmail.com.

${ }^{2}$ Doutora pelo Programa de Pós-Graduação em Ciência Política; Universidade Federal de Pelotas; Pelotas, Rio Grande do Sul; Brasil; patchavescunha@ gmail.com.
} 
rates, among others, using the "sex" variable. Thus, the objective would be comprehending the transformations occurred in this city from 2000, 2010 and 2015 measuring the absorption levels of the female workforce in this period of time. Based on these factors the preoccupation is over perceiving women's conditions for action within the economic field in the city. Therefore, perceiving the representation of women in the labor market.

Keywords : Labor Markets, Inequality, Women, Pelotas/RS.

\section{Introdução}

A participação das mulheres no mercado de trabalho é um fenômeno recente na sociedade capitalista. Por meio de muitas lutas dos movimentos feministas, a desigualdade em relação aos homens tem diminuído ao longo dos anos. Especialmente na cidade de Pelotas a inserção feminina na economia tem crescido na última década. Este município que registra cerca de 328.275 mil habitantes, registrados no último censo de 2010, é a terceira cidade mais populosa no estado do Rio Grande do Sul. O número de mulheres também é significativo, correspondendo a 53\% da população residente. Através dos níveis participação econômica das mulheres, no mercado de trabalho desta cidade é possível observar a condição feminina enquanto agente ${ }^{2}$ econômico. Além disso, é verificada que há uma divisão sexual do trabalho, categoria analítica que proporciona verificar as relações sociais no mercado de trabalho, do ponto de vista das distinções entre os papéis profissionais que são desempenhados nele. Desta maneira pode-se observar como a força de trabalho feminina é distribuída em relação à masculina e o seu peso econômico na cidade.

Assim, este estudo tem por objetivo analisar os dados sobre a participação das mulheres no mercado de trabalho local. Além disso, comparar os dados femininos e masculinos, observando as suas assimetrias. Assim, propõe-se um balanço das transformações ocorridas no mercado de trabalho, identificando em que medida as desigualdades de gênero se manifestam nesse cenário.

Os dados utilizados foram levantados a partir da fonte de referência os Censos de 2000 e de 2010 do Instituto Brasileiro de Geografia e Estatística (IBGE). A finalidade é de realizar um panorama das transformações do mundo do trabalho do município, bem como os níveis das populações economicamente ativa (PEA), população não economicamente ativa (PNEA), ocupada (PO), desocupada (PD) e taxas de atividade e desemprego. Estas são categorias estatísticas importantes para se caracterizar a estrutura populacional do mercado de trabalho. Por meio desses elementos é possível estabelecer também as diferenças quantitativas entre os

\footnotetext{
${ }^{2}$ Agente, neste sentido é defino como “[...]membro do público e como participante de ações econômicas, sociais e políticas [...]” (SEN, 2000, p. 33).
} 
sexos e mensurar os níveis de participação das mulheres, na vida econômica da cidade. Outro ponto é perceber o crescimento desta participação no período de dez anos e as transformações do mercado de trabalho. Além disso, foram levantados dados da RAIS (Relação Anual de Informações Sociais) para verificar as discrepâncias em relação aos rendimentos entre homens e mulheres.

\section{Divisão sexual do trabalho}

A divisão social do trabalho, categoria criada inicialmente por Adam Smith e desenvolvida por Émile Durkheim é uma análise importante para se compreender a divisão sexual do trabalho. A proposta parte do conceito de função, definida como as atividades que cada um desempenha na sociedade. Por exemplo, o padeiro de que faz o pão, o agricultor que colhe o trigo. Os dois juntos formam um sistema de trocas em que um depende diretamente do outro para produzir. Cada um exerce uma função na divisão social do trabalho. Desta forma o autor coloca que a sociedade é movida por um conjunto de vínculos sociais distribuídos nos diferentes papéis que as pessoas desempenham. A diversidade é um elemento interessante pois quanto mais diferentes formos uns dos outros, melhor para a sociedade pois haverá mais articulações em relação a distribuição de laços sociais. Para Durkheim a complementaridade de diferentes funções é o que dá sentido a solidariedade social. Assim:

\footnotetext{
Um protege, o outro consola; este aconselha, aquele executa, e é essa partilha de funções, ou, para empregarmos a expressão consagrada, essa divisão do trabalho que determina essas relações de amizade. Somos levados, assim, a considerar a divisão do trabalho sob um novo aspecto. Nesse caso, de fato, os serviços econômicos que ela pode prestar são pouca coisa em comparação com o efeito moral que ela produz, e sua verdadeira função é criar entre duas ou várias pessoas um sentimento de solidariedade. (DURKHEIM, 99, pg. 31)
}

Em relação à solidariedade social existe o aspecto jurídico que materializa simbolicamente os vínculos entre os sujeitos. Desta forma estas ligações se estruturam a partir das regulamentações que orientam as relações sociais. Os contratos estabelecem os direitos entre ambas às partes para que se evitem conflitos ou por meio de leis que dão limites a sociabilidade, baseados nos valores e aspectos morais que determinam a sociedade. Mas nem tudo é regulamentado pelo direito. Existe outra característica, mais subjetiva, que define o fenômeno. Por meio dos costumes e valores pode - se perceber a socialização entre os sujeitos. A vista disso é notável que alguns costumes podem se opuser aos que o direito positivo estabelece. Contudo, essa oposição se dará em casos excepcionais que podem ser 
inclusive formas anormais de socialização. O que Durkheim estabelece que os costumes sejam que o proporciona a base para a construção jurídica e geralmente não se opõe a ele.

Outro ponto relevante a ser observado é a maneira como o sociólogo examina as relações sociais. Adepto da corrente naturalista e baseado no método positivista de Comte, ele busca estabelecer as relações de causa e efeito para compreender os fenômenos sociais. Esta análise é fundamentada nas ciências naturais e busca estabelecer leis explicativas. Este rigor metodológico é o que da base à construção do pensamento científico das ciências sociais, neste período em que ela é construída. Dentro disso compreende-se que a divisão social do trabalho é a causa e a solidariedade social o efeito. É no sentido de complementaridade que as relações sociais e funcionais consolidam a solidariedade. Neste modo de observação, a divisão sexual do trabalho se insere, dentro da dimensão da reciprocidade entre os papéis de gênero articulados com a forma como os homens e mulheres se diferenciam nos seus aspectos fisiológicos e biológicos.

Cabe salientar que a fundamentação está pontuada numa noção evolucionista da sociedade. A complementaridade é ainda trabalhada nesta perspectiva, porém, comparações fisiológicas em relação ao corpo do homem e da mulher são realizadas, de um ponto de vista determinista. Conforme a divisão social do trabalho:

Enquanto a média dos crânios parisienses masculinos coloca-os entre os maiores crânios conhecidos, a média dos crânios femininos coloca-os entre os menores crânios observados, bem abaixo do crânio das chinesas e apenas acima do crânio das mulheres da Nova Caledônia, diz ele. (Lebon, citado por Durkheim, 1999, pg. 26)

É importante ressaltar que no século XIX o evolucionismo cultural está em destaque, que é também elemento do positivismo de Comte, cientista que influência o pensamento durkheimiano. Auguste Comte se baseia na teoria da evolução das espécies de Charles Darwin. Contudo, com as pesquisas desenvolvidas por Franz Boas, esta corrente teórica é deixada de lado principalmente por seu viés de naturalização de aspectos culturais que não cabem para comparar e classificar aspectos que são construídos socialmente. Neste sentido, têm-se observações relativas em relação ao que define evolução contra um argumento focado no determinismo biológico. O relativismo cultural é uma perspectiva que refuta a teoria evolucionista. Boas revisou os pressupostos teóricos e metodológicos a fim de negar a existência de natureza humana imutável. Conforme Pereira

Boas critica teorias deterministas aplicadas ao estudo da cultura humana, como, por exemplo, o determinismo geográfico e econômico.[...] mostra que as funções e os 
traços fundamentais da mente humana são idênticos e que, portanto, o processo educacional, pode levar uma pessoa a desenvolver seu raciocínio, independentemente da parte do planeta em se vive. (2011, pg. 104-105).

Assim por mais que as diferenças sexuais possam ser analisadas pelas diferenças fisiológicas, o comportamento masculino e feminino é moldado pela sociedade, isto é, não é predeterminado biologicamente e sim que pode ser construído por meio da educação. Durkheim reconhece este aspecto quando coloca as diferenças entre mulheres de outras culturas. Desta forma, ele pontua:

Em Cuba, no Daomé, elas são tão guerreiras quanto os homens e lutam ao lado deles. Um dos atributos hoje distintivos da mulher, a doçura, já não parece ter-lhe pertencido primitivamente. Já em certas espécies animais, a fêmea faz-se notar muito mais pelo caráter contrário. (DURKHEIM, 99, pg. 26)

Todavia mesmo percebendo estas discrepâncias ele elenca tais comportamentos dentro de uma linha evolucionista. Nesta visão, sociedades antigas são desvalorizadas em relação à sociedade europeia do século XIX. Esta ultima, considerada como o ponto máximo de desenvolvimento humano.

Por outro lado, os estudos franceses sobre a divisão sexual do trabalho possuem argumentos antagônicos em relação ao pensamento funcionalista. Outrossim eles compartilham grande relevância na luta feminista por direitos sociais. Hirata e Kergoat colocam que as relações de gênero possuem um caráter de dominação. Se opondo a perspectiva funcionalista, elas se baseiam no materialismo histórico dialético, perspectiva de Marx, para compreensão dos fenômenos sociais. Esta análise parte das condições materiais de existência para a compreensão das diferenças entre as variáveis. Com isso não serão as relações e vínculos estabelecidos, no que eles se conectam, mas sim os antagonismos, considerando as trajetórias históricas e a circunstância em que os sujeitos se encontram. Percebe-se que a principal diferença está fundamentada na relação entre sujeito e objeto. Desta maneira, se define que o trabalho é um elemento que transforma a matéria e desta maneira modifica a realidade social, pois muda o olhar em que a humanidade visualiza a natureza. Assim ao transformar as estruturas materiais de existência com o trabalho o homem modifica a si mesmo. Esta diferenciação em relação à Durkheim é um ponto central na compreensão da perspectiva de Hirata e Kergoat, pois pontua que as relações de gênero no mercado de trabalho são relações que não implicam determinismos biológicos. Além disso, é por meio do antagonismo de forças entre homem e mulher em que a divisão sexual do mercado de trabalho esta pautada, sendo esta também articulada a estruturas hierárquicas. 
Desta maneira os papeis profissionais não são dados a priori e sim dentro de uma relação de força que se modifica dado o tempo histórico e as condições materiais de existência dos sujeitos envolvidos. Segundo Kergoat, "as relações sociais têm propriedades comuns - daí o emprego do conceito marxiano de relação social com seu conteúdo dialético e materialista para pensar, também, o sexo e a raça [...]" (2016, pg. 20).

Além disso, existe a diferença de valor entre o trabalho feminino e masculino e suas implicações na distribuição de ocupações e rendimentos. Neste sentido, podemos considerar uma dimensão antropológica e ética que implica numa hierarquia social que também é pensada como relação social. Logo: "Valor e princípio de hierarquia, sob aparências múltiplas, permanecem imutáveis: o trabalho de um homem pesa mais que o trabalho de uma mulher.“ (HIRATA, H. \& KERGOAT, D. 2003. pg 113). Esta observação é importante para analisar as diferenças de rendimento dos homens e das mulheres.

Assim pode-se constatar que há implicações pontuais em relação às duas abordagens debatidas, nesta análise é entendida que tanto a noção de complementaridade como de antagonismo são importantes para a observação do fenômeno. Entretanto homens e mulheres são vistos como iguais frente a sua distribuição no mercado de trabalho e suas diferenças só possuem sentido na caracterização e distinção entre os sujeitos e não justifica as desigualdades observadas na exposição dos dados.

\section{Resultados e discussão}

No município de Pelotas, conforme Tabela 1, observa-se que apesar de os homens e as mulheres aumentaram a disponibilidade de sua participação na população economicamente ativa $(\mathrm{PEA})^{3}$, a participação masculina passou de 85.246 homens (56\%), em 2000, para $86.700(53,6 \%)$, em 2010, variando em 1,7\%. A participação feminina passou de 66.849 mulheres (44\%) para 75.007 (46,4\%), tendo variação de 12,2\%, no mesmo período.

De 2000 á 2010 a participação feminina na população não economicamente ativa (PNEA), sofreu uma queda, na variação, de 3,9\%, passando de $76.981(65,1 \%)$ para 80.003 $(62,9 \%)$, enquanto a participação da população masculina teve um acréscimo de 14,3\%, passando de $41.351(34,9 \%)$ para $47.274(37,1 \%)$. Todavia, a taxa de atividade ${ }^{4}$ entre os homens é maior do que em relação às mulheres, numa diferença de 20,8\% em 2000. Com

\footnotetext{
${ }^{3}$ População Economicamente Ativa (PEA) - É composta pelas pessoas de 10 a 65 anos de idade que foram classificadas como ocupadas ou desocupadas na semana de referência da pesquisa, conforme o conceito utilizado pelo IBGE.

${ }^{4}$ Taxa de atividade - percentagem das pessoas economicamente ativas, em relação às pessoas de 10 ou mais anos de idade, conforme a definição do IBGE.
} 
isso temos as taxas feminina e masculina, respectivamente, que chegam a 46,5\% e 67,3\% em 2000, passando para 48,4\% e 64,7\% em 2010. Neste sentido, podemos observar que as diferenças entre os sexos caíram 4,5\% na última década, chegando a 16,3\% em 2010. Este dado indica uma diminuição da desigualdade. Isso demonstra uma inserção maior da mão obra feminina no mercado de trabalho da cidade de Pelotas. A condição da mulher como agente econômico se intensifica, mas não se iguala aos números dos homens. Neste sentido Sen (1999, p. 21) levanta a importância de se participar do mercado de trabalho para o desenvolvimento humano em oposição a outras formas de trabalho não remuneradas. Em vista disso, percebemos como mostram os dados, que os homens possuem mais oportunidade de atuação na economia da cidade do que as mulheres, apesar das diferenças terem caído. Esta relação se dará pela definição de PEA que representa a população apta a estar sendo inserida no mercado de trabalho enquanto a PNEA não disponível para o mesmo. Sobre o mercado e trabalho no Brasil, as políticas públicas de geração de emprego e renda são criadas e ampliadas, neste período, para populações consideradas vulneráveis, observando-se a expansão da PEA feminina também no país (IPEA, 2006). Outro fator que explicaria este aumento são os aspectos demográficos, já que houve um aumento também da população residente que passou de 323.034 para $328.275 \mathrm{em} \mathrm{dez}$ anos, num aumento de 5.241 em números absolutos. Isso poderia explicar o aumento da participação feminina em termos demográficos.

Em relação aos níveis de ocupação feminina, que indica a quantidade de mulheres que possuem trabalho ${ }^{5}$, compreendido como atividade econômica remunerada ou não remunerada que produza bens, serviços sejam no setor privado ou na produção de seu próprio consumo. Entre os efetivamente ocupados (PO), os homens também eram maioria em 2000, com uma população de 72.843 (57,9\%) em oposição às mulheres com 52.925 (42,1\%). A diferença, em termos relativos fica em 15,8\%. Em 2010, houve um crescimento destas populações. As mulheres passaram para $67.657(45,3 \%)$ e os homens $81.815(54,7 \%)$. A diferença cai percentualmente chegando a $9,4 \%$. Nesta categoria percebemos uma diminuição significativa nas desigualdades, demonstrando que há mais mulheres atuando no mercado de trabalho e menos homens. Esta classificação é importante, pois indica a população que está efetivamente atuando no mercado de trabalho enquanto a PEA indicaria a disponibilidade de oferta de força de trabalho. Como mostram os dados a um aumento da mão de obra feminina. Isso se percebe na diminuição das taxas de desemprego que em 2000 representavam 20,8\% das mulheres e

\footnotetext{
${ }^{5}$ Nota técnica do IBGE.
} 
passam para $9,8 \%$. Os homens de $14,5 \%$ chegam a 5,6\%. A diferença das taxas entre ambos cai de $6,3 \%$ para $4,2 \%$. Essa disparidade é demonstrada no aumento das taxas de atividade feminina, como já foi colocado anteriormente.

Tabela 1. População Não Economicamente Ativa (PNEA), População Economicamente Ativa (PEA), População Ocupada (PO), População Desocupada (PD), Taxa de atividade e desocupação, Pelotas, 2000 e 2010.

\begin{tabular}{|c|c|c|c|c|c|c|c|c|}
\hline \multirow{2}{*}{ Município de Pelotas } & \multicolumn{4}{|c|}{2000} & \multicolumn{4}{c|}{2010} \\
\cline { 2 - 11 } & \multicolumn{2}{|c|}{ Mulheres } & \multicolumn{2}{c|}{ Homens } & \multicolumn{2}{c|}{ Mulheres } & \multicolumn{2}{c|}{ Homens } \\
\cline { 2 - 10 } & $\mathbf{N}^{\mathbf{0}}$ & $\mathbf{\%}$ & $\mathbf{N}^{\mathbf{0}}$ & $\mathbf{\%}$ & $\mathbf{N}^{\mathbf{0}}$ & $\mathbf{\%}$ & $\mathbf{N}^{\mathbf{0}}$ & $\mathbf{\%}$ \\
\hline PNEA & 76.981 & 65,1 & 41.351 & 34,9 & 80.003 & 62,9 & 47.274 & 37,1 \\
\hline PEA & 66.849 & 44,0 & 85.246 & 56,0 & 75.007 & 46,4 & 86.700 & 53,6 \\
\hline PO & 52.925 & 42,1 & 72.843 & 57,9 & 67.657 & 45,3 & 81.815 & 54,7 \\
\hline PD & 13.924 & 52,9 & 12.403 & 47,1 & 7.350 & 60,1 & 4.885 & 39,9 \\
\hline Taxa de Atividade & $46,5 \%$ & \multicolumn{2}{|c|}{$67,3 \%$} & 48,4 & 64,7 \\
\hline Taxa de Desocupação & \multicolumn{2}{|c|}{20,8} & \multicolumn{2}{|c|}{14,5} & \multicolumn{2}{c|}{9,8} & 5,6 \\
\hline
\end{tabular}

Fonte: IBGE, Censos demográficos de 2000 e 2010.

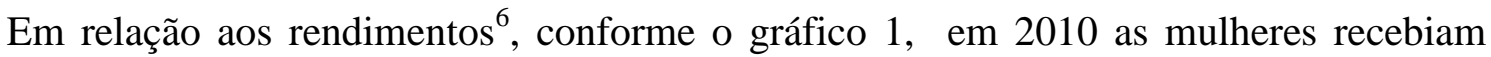
$85 \%$ do salário dos homens. Com o aumento do salário mínimo em 2015, verifica-se que as mulheres passaram a receber apenas 3,5\% a mais, sendo remuneradas com $89 \%$ em relação as salário dos homens. O calculo da razão entre remunerações ocorre considerando a divisão entre duas grandezas da mesma categoria. Para que ocorra igualdade salarial o número devese chegar a $100 \%$, isto é 1 para 1.

Gráfico 1. Razão entre as Remunerações, por sexo. Pelotas 2010 á 2015.

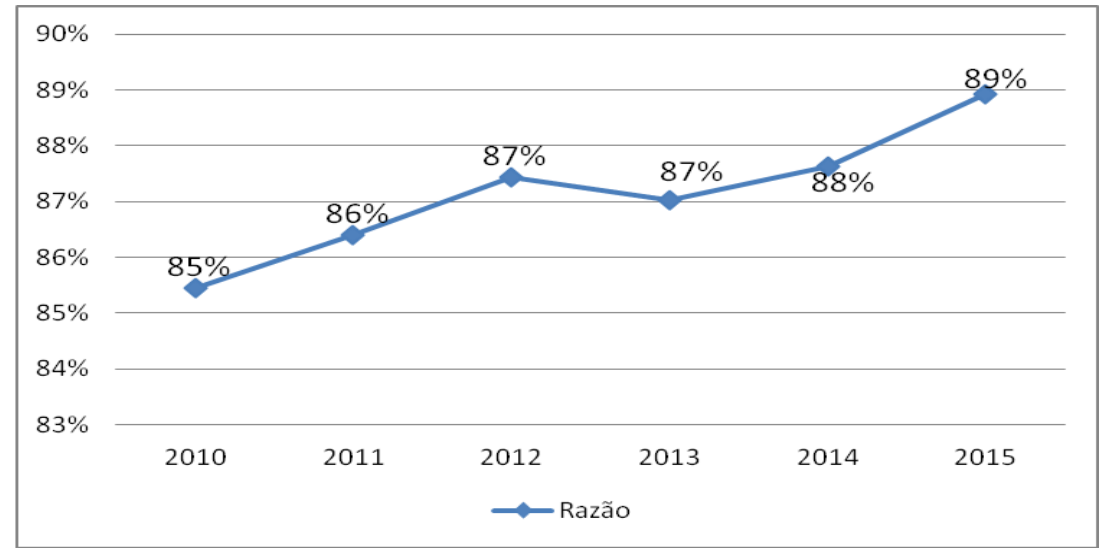

Fonte: RAIS vínculos, acesso em 30 de outubro de 2017.

\footnotetext{
${ }^{6}$ Rendimentos: representa a remuneração média nominal ou em salários mínimos, no período vigente do anobase da força de trabalho empregada. Para efeito estatístico, não são consideradas as remunerações referentes ao $13^{\circ}$ salário. Nota Técnica MTE (09/09/2015)
} 


\section{Considerações Finais}

Podemos constatar que, em termos quantitativos, as mulheres são minoria no mercado de trabalho formal, contudo temos transformações relevantes nos dados do Censo de 2000 e 2010. O aumento demográfico e as políticas de geração de emprego e renda que se desenvolvem a partir dos anos 1990 e são intensificadas nos anos 2000, colaboraram para a diminuição das taxas de desecupação na cidade e são uma consequência do cenário nacional. O impacto na cidade de Pelotas é significativo, promovendo uma maior inserção da população no mercado de trabalho. As diminuições das desigualdades e a intensificação da participação feminina são um resultado importante nas lutas pela igualdade entre os sexos. Todavia, a desigualdade é diminuída, mas não é eliminada. É notória a necessidade de políticas públicas voltadas para as mulheres, no sentido de expandir a sua capacidade de agenciar-se e ser responsável pelo cuidado de si e das pessoas que estão a sua volta. A promoção da autonomia da mulher é um fator que colabora com outras situações de privacidade de liberdades substantivas que conforme Sen: “[...] a liberdade de troca e transação é ela própria uma parte essencial das liberdades básicas que as pessoas tem razão para valorizar” (1999, p. 21). Em relação a divisão sexual do trabalho, compreende -se que os pontos levantados são descritos nos dados de forma empírica. Nos rendimentos, percebe-se que essas diferenças são expressivas em que num período de cinco anos não se atingiu igualdade salarial, por mais que tivessem ocorrido políticas publicas voltadas para a inserção da mulher no mercado de trabalho. Compreende-se que estas ações não impactaram este ponto, de grande relevância para a promoção da valorização do trabalho feminino.

Assim, a luta por direitos de igualdade no mercado de trabalho formal ainda é um longo caminho a ser percorrido. A criação de oportunidades econômicas e valorização da mão de obra feminina é o próximo desafio para as políticas públicas no município de Pelotas.

\section{Referências}

Brasil: o estado de uma nação - mercado de trabalho, emprego e informalidade, 2006/ Paulo Tafner, editor. - Rio de Janeiro: IPEA, 2006.

BRUSCHINI, Cristina; RICOLDI, Arlene Martinez; MERCADO, Cristiano Miglioranza. Trabalho e gênero no Brasil ate 2005: uma comparação regional. In: COSTA, Albertina de Oliveira; SORJ, Bila; BRUSCHINI, Cristina; HIRATA, Helena (Org). Mercado de Trabalho e Gênero. Rio de Janeiro: Editora FGV, 2008.

KERGOAT, D. O cuidado e a imbricação das relações sociais. In Hirata, Helena; Lombardi, Maria Rosa (orgs.) Gênero e Trabalho no Brasil e na França. Perspectivas interseccionais. São Paulo: Boitempo, 2016. 
KERGOAT, D. \& HIRATA, H. A divisão sexual do trabalho revisitada. In: MARUANI, M. \& HIRATA, H. (Org.). As novas fronteiras da desigualdade. Homens e mulheres no mercado de trabalho. São Paulo: Editora Senac, 2003.

MARUANI, MARGARET. Emprego, desemprego e precariedade: uma comparação européia. In: COSTA, Albertina de Oliveira; SORJ, Bila; BRUSCHINI, Cristina; HIRATA, Helena (Org). Mercado de Trabalho e Gênero. Rio de Janeiro: Editora FGV, 2008.

PEREIRA, José Carlos. Educação e cultura no pensamento de Franz Boas. In: Ponto-evírgula: revista do Programa de Estudos Pós-graduados em Ciências Sociais da PUC-SP. No $10,2^{\circ}$ semestre de 2011. P. 101-118.

SEN, Amartya. Desenvolvimento como liberdade. São Paulo: Companhia das Letras, 2010.

VARGAS, Francisco. Desenvolvimento e desigualdades de gênero: As transformações no mercado de trabalho em Pelotas e Rio Grande. In: Dal Molin, N. \& Figueiredo, C. Políticas Públicas e Desenvolvimento nos municípios gaúchos de Pelotas e Rio Grande. Porto Alegre: Cirkula, 2014. 